\title{
Diabetes related cataract and histopathological abnormalities of the ocular regions of Wister albino rats
}

\author{
El-Sayyad $\mathrm{HIH}^{1 *}$, El-Beih $\mathrm{ME}^{1,2}$, Yousra A. Fouda ${ }^{1,3}$, AljebaliA ${ }^{4}$ \\ ${ }^{1}$ Department of Zoology, Faculty of Science, Mansoura University, Mansoura, Egypt \\ ${ }^{2}$ Biology Department, El-Jumum College, University Umm El-Qura, KSA \\ ${ }^{3}$ Biology Department, Faculty of Science \& Art, Baha University, KSA \\ ${ }^{4}$ Department of Zoology, Faculty of Science, Omar Al-Mukhtar University, Bayda, Libya \\ *Corresponding author: El-Sayyad HIH, Department of Zoology, Faculty of Science, Mansoura University, Mansoura, Egypt; E-mail: elsayyad@mans.edu.eg
}

Received: April 30, 2019; Accepted: May 06, 2019; Published: June 09, 2019;

\begin{abstract}
Objective: Diabetes is an important public health disease affected different body organs especially eye. The present study aimed to illustrate the cataractous lenses associated complication on ocular organs.

Research design and methods: Following induction of type 2 diabetes for 6 months (streptozotocin $60 \mathrm{mg} / \mathrm{kg}$ single dose in combination with nicotinamide100 mg./kg body weight), 6 rats of a colony of 47 individuals developed cataract. Control individuals were used of the similar age. The animals groups were anaesthetized and sacrificed. Ocular regions were incised and subjected for histopathology and comet assay. Transmission electron microscopy was carried out for the optic nerve. In case of meibomian gland, beside histopathological investigations, immunohistochemistry of bcl2, caspase 3 and p53 were carried out.
\end{abstract}

Results: The present findings revealed the development of cataractous lenses, diabetic retinopathy, thickened cornea and damaged stroma and optic neuropathy explained by demyelinated axons. Single gel electrophoresis explained DNA damage of cells of the retina, ciliary organ and optic nerve. Also, there is a marked reduction of the immunohistochemistry of bcl2, caspase 3 and p53 of diabetic meibomian gland, reflecting cell death.

Conclusion: Finally the authors concluded that the cataractous lenses originated through different pathways of diabetic complication.

\section{Introduction}

The Diabetes Mellitus (DM) is characterized by hyperglycemia associated with either decreased insulin production in the body or insulin resistance. It is increased among population reached up to 382 million in 2014 [1] and by 2035 more than 592 million may develop with the disease in a ratio of 1 per 10 individual become diabetic [2]. The disease resulted from impairing of $\beta$-cell function, hyperglycaemia and impairment of insulin secretion [3].

Poor diabetic-treatment resulted in impairment of visual acuity [4] and the development of cataract in child hood $[5,6]$. Cataractous lenses were also reported in diabetic experimental animal [7]. Diabetic related cataract was associated with damaging corneal endothelial cells and increase foveal thickness [8]. Also, diabetic was found to induce retinopathy $[9,10]$ and represent the main cause of impaired visual acuity and blindness associated with elevated serum homocysteine level Hcy [11]. Also, it is involved in reduction of both retinal thickness and retinal blood flow, and increased thickening of the retinal choriocapillaries [12]. The disease increased retinal apoptosis, overexpression of VEGF and increased oxidative stress [13, 14] and altered osmoregulation leading to acidic retina [15]. Middle-aged, obese rhesus monkeys, developed diabetes mellitus characterized by hypertension, high levels of triglycerides and serum cholesterol. The disease associated with intraretinal hemorrhages, damage choriocapillaries, increased basal laminar deposits and hard drusen of Bruch's membrane and numerical reduction of photoreceptor inner and outer segments [16]. Diabetic retinopathy characterized by upregulation of pro-inflammatory interleukin- 6 and down-regulation of superoxide dismutase and glutathione (GSH)/oxidized glutathione associated with numerical reduction of retinal ganglion cells and increased glial fibrillary acidic protein expression level [17-18].

Concerning cornea which is the transparent organ important for vision. Diabetes caused marked degeneration of corneal secondary nerve fiber branches $[19,20]$ and enhanced the development of anterior segment disorders such as corneal erosion and ulcer and persistent epithelial defects [21]. There is discrepancy between authors concerning diabetic interference on corneal thickness. Meanwhile Olsen and Busted (1981) [22] reported increased corneal thickness in diabetic patients, Hashemi et al. (2019) [23] reported no variations of corneal thickness between diabetic and non diabetic individuals. Diabetic keratopathy resulted in reduction of corneal sensitivity [24].

The ocular region guards by eye lid containing glands such as the meibomian glands (MGs) which are arranged in parallel strands within the tarsal plates of the eyelids. It secrete oily meibum by meibocytes and transported through the ductal system by ductule and the central duct towards the free lid margin. The gland possesses a characteristic innervations from sympathetic and parasympathetic 
fibers $[25,26]$. The meibum lubricating the ocular surface during blinking and protecting against tear evaporation [27].

Diabetes was found to induced meibomian gland dysfunction $[28$, 29] leading to depletion of the lipid secretion associated the instability of tear and development of dry eye disease [27, 30].

Little is known about the diabetes related changes on the histopathological structure of the meibomian glands. Recently, a study from Ding et al. demonstrated that insulin stimulated the proliferation of immortalized human meibomian gland epithelial cells (HMGECs), whereas high glucose was found to be toxic for HMGECs [31]. Diabetes was found to reduce the number of glandular structure impairing its functional activity [32]. Also, diabetes was found to be involved in increase of ciliary body thickness [33] and reduction of both retinal nerve fiber layer and vessel density in the optic disc [34].

The present studies searched for illustrating if the opacity associated with other complication of the eye regions or not and the characteristic features of the histopathological alterations.

\section{Materials and Methods}

\section{Induction of diabetes}

Experimental type 2 diabetes mellitus was induced in all the rats by a single interperitoneal injection of streptozotocin $(60 \mathrm{mg} / \mathrm{kg})$ in citrate buffer $(0.05 \mathrm{M})(\mathrm{pH} 4.5)$ and $100 \mathrm{mg} / \mathrm{kg}$ ncotinamide [35]. Hyperglycemia was verified by measuring the blood glucose within 240- $280 \mathrm{mg} / \mathrm{dl}$ were selected for the study.

\section{Experimental animals}

Following investigating a colony of 47 individual diabetic rats (Rattusnorvegicus) after 8 months of streptozotocin-induction and weighing approximately $200-250 \mathrm{~g}$ body weight, 6 rats exhibiting cataractous lenses either unilateral $(4 / 6)$ or bilateral (2/6). Control healthy individuals $(n=6)$ were selected. They were housed in good ventilation on a 12 -h light and dark cycle. The studied cataractous rats were observed in about 47 individual diabetic rats after 6 months of induction the disease reaching incidence of about $13 \%$. The cataractous group was separated and a similar control non-diabetic group was also selected. Free excess water and food were allowed ad Libitum. The studied groups were sacrificed by light diethyl ether anesthesia and dissected and ocular region, upper eye lid and optic nerves were separated and processed for the following investigations.

\section{Histological investigation}

Retina, cornea, proximal optic nerve, ciliary organ and upper eye lid of the studied groups were separated and immediately fixed in $10 \%$ phosphate buffered formalin ( $\mathrm{pH}$ 7.4), dehydrated in ascending grades of ethyl alcohol, cleared in xylene and mounted in molten paraplast at $58-62^{\circ} \mathrm{C}$. Five $\mu \mathrm{m}$ histological sections were stained with hematoxylin \& eosin and investigated under a bright field light microscope.

\section{Immunohistochemistry for caspase 3}

Histological $5 \mu \mathrm{m}$ thick sections of upper eye lid were cut and mounted onto super frost plus glass slides (Fisher Thermo Scientific, Nepean, Ontario, Canada). The tissue sections were retained at normal room temperature and processed for antigen retrieval by digestion in $0.05 \%$ trypsin ( $\mathrm{pH} 7.8$ ) for $15 \mathrm{~min}$ at $37^{\circ} \mathrm{C}$ and incubated with antibodies against bcl2, caspase 3 and P53 (dilution 1:100 Thermo Fisher Scientific, Fremont, CA, USA; Cat. No. A1-70007) for overnight at $4^{\circ} \mathrm{C}$. Then treated with a horseradish peroxidase streptavidin detection system (Dako), followed with DAB plus Chromagen to detect the immunoactivity by counterstaining with hematoxylin (Sigma). Sections incubated with $1 \%$ non-immune serum phosphate buffer solution (PBS) solution served as negative controls. Specimens were observed with a Leica BM5000 microscope (Leica Microsystems, Wetzlar, Germany) and photographed. For assessments of the percentages of positive immunoreactive areas were determined by investigating slides using Olympus ${ }^{\circledR}$ digital camera installed on Olympus ${ }^{\circledR}$ microscope with $1 / 2$ X photo adaptor, using $40 \mathrm{X}$ objective. The result images were analyzed on Intel ${ }^{\circledR}$ Core $\mathrm{I} 5^{\circledR}$ based computer using Video Test Morphology ${ }^{\circledR}$ software (Russia) with a specific built-in routine for area, \% area measurement and object counting.

\section{Transmission electron microscopy}

Specimen of proximal optic nerve close to the retina of the studied groups were immediately fixed in $0.1 \mathrm{M}$ cacodylate buffer ( $\mathrm{pH} 7.4)$ containing $2.5 \%$ glutaraldehyde) and post-fixed in $1 \%$ osmium tetraoxide, dehydrated in ascending grades of ethyl alcohol, and embedded in epoxy-resin. Ultrathin sections were cut with a diamond knife on a LKB Ultratome IV (LKB Instruments, Bromma, Sweden) and mounted on grids, stained with uranyl acetate and lead citrate, and examined under a Joel 100CX transmission electron microscope (Musashino 3-chome, Akishima, Tokyo 196-8558, Japan).

\section{Comet assay}

Retina, cornea, optic nerve, ciliary organ specimens of the studied groups were homogenized in chilled homogenizer buffer, $\mathrm{pH}$ 7.5, containing $75 \mathrm{mMNaCl}$ and $24 \mathrm{mM} \mathrm{Na}_{2}$ ethylenediaminetetraacetic acid (EDTA), pH 13. Six $\mu \mathrm{L}$ of the homogenate were suspended on $0.5 \%$ low melting agarose and sandwiched between a layer of $0.6 \%$ normal-melting agarose and another of $0.5 \%$ low melting agarose on fully frosted slides and kept on ice for the polymerization. The slides were the immersed in a lysis solution (1\% sodium surcosinate, $2.5 \mathrm{M}$ $\mathrm{NaCl}, 100 \mathrm{mM} \mathrm{Na}_{2}$ EDTA, $10 \mathrm{~mm}$ Tris-HCl, $1 \%$ Triton X-100, and 10\% DMSO) at $4^{\circ} \mathrm{C}$. After $1 \mathrm{~h}$, they were placed in electrophoresis buffer (0.3 $\mathrm{M} \mathrm{NaOH}, 1 \mathrm{mM} \mathrm{Na}{ }_{2}$ EDTA, $\mathrm{pH}$ 13) for $10 \mathrm{~min}$ at $37^{\circ} \mathrm{C}$ to allow DNA to unwind. Electrophoresis was carried out for $10 \mathrm{~min}$ at $300 \mathrm{~mA}$ and $1 \mathrm{~V} / \mathrm{cm}$, followed by staining with $20 \mathrm{mg} / \mathrm{mL}$ ethidium bromide. Each slide was analyzed using a Leitz Orthoplan (Wetzlar, Germany) epifluorescence microscope. One hundred cells were analyzed on each slide using the Comet assay II automatic digital analysis system. Perspective tail length $(\mathrm{mm})$ is the distance of DNA migration from the center of the body of the nuclear core and is used to evaluate the extent of DNA damage. Tail length was measured automatically by image analysis software [36].

\section{Statistical analysis}

Data are presented as means \pm standard deviation (SD). The statistical analysis was performed with multi-variant analysis of 
variance (MANOVA) using the SPSS (version 13) software package for Windows, comparing the multivariations between diabetes and control groups. Significance was determined at $\mathrm{p}<0.05$

\section{Results}

\section{Cornea \& Retina}

The cornea is composed of outer lining epithelium, followed by Bowman's membrane, stroma, descemet's membrane and corneal endothelium. Regard to the control (Fig. 1A), the diabetic group revealed that the corneal epithelium was comparatively thickened with vesicular vacuolar degenerated nuclei. The stroma showed patches of hyaline degenerated collagenous fibrils and infiltrated by necrotic regions. Vacuolated keratocytes were detected in between the collagen fibrils of the stroma. The corneal endothelium lining the descemet's membrane attained considerable thickening (Fig. 1A1).

Regarding to the normal structure of the retina (Fig, 1B ), the diabetic group showed comparative reduction of the retinal thickness. There was comparative numerical reduction of the inner and outer nuclear cells. The nuclei of these cell layer were electron-dese manifesting clumping of the nuclear chromatin. The photoreceptor layer was comparatively atrophied. The ganglion cells were markedly missing and the nerve fiber become thin, fragile and vacuolated (Fig.1B1). Diabetic retina showed detached retinal cells manifesting damaged DNa (Fig. 1C1) compared to non-changed in control (Fig.1C). The whole retina, inner and outer nuclear layer and photoreceptors attained considerable reduction in diabetic group in comparison with the control (Fig. 2).

\section{Ciliary organ and optic nerve}

The ciliary body occupied the interface between the iris and the choroids. It is made up of two ring-shaped components: the pars plicata and the pars plana. The parsplicata detected in the anterior region of the ciliary body, at the scleral spur. The ciliary body composed of branched ciliary processes. It is lined by two layers of columnar cells. The outer one is pigmented, mean while the inner lining cells lack pigmentation. The lumen is enclosed with fine collagenous network (Fig. 3 A). Following application of comet assay the control ciliary cells are round (Fig.3A1).

Experimental diabetic group revealed missing of the ciliary processes and comparative thinning of their lining epithelium. Congestion of their blood capillaries, widened lumen and distortion of their collagenous network were observed (Fig. 3B). Following single gel electrophoresis (comet assay), revealed DNA segregation assessed by formation of detached tail region manifested DNA damage (Fig. 3B1).

\section{Optic nerve}

Concerning the optic nerve, light microscopically, these are formed of densely aggregated and enclosed in-between cells with basophilic nuclei suspected the oligodendrocytes and astrocytes (Figs. $3 \mathrm{C} \& \mathrm{C} 1)$. Ultrastructurally, the nerve axons are densely packed and composed of myelinated and non-myelinated axons of varying small size. The axon enclosed by several layers of myelin sheath. Abundant mitochondria are distributed the cytoplasm of the inner compartment of the axons (Fig.3 C2).

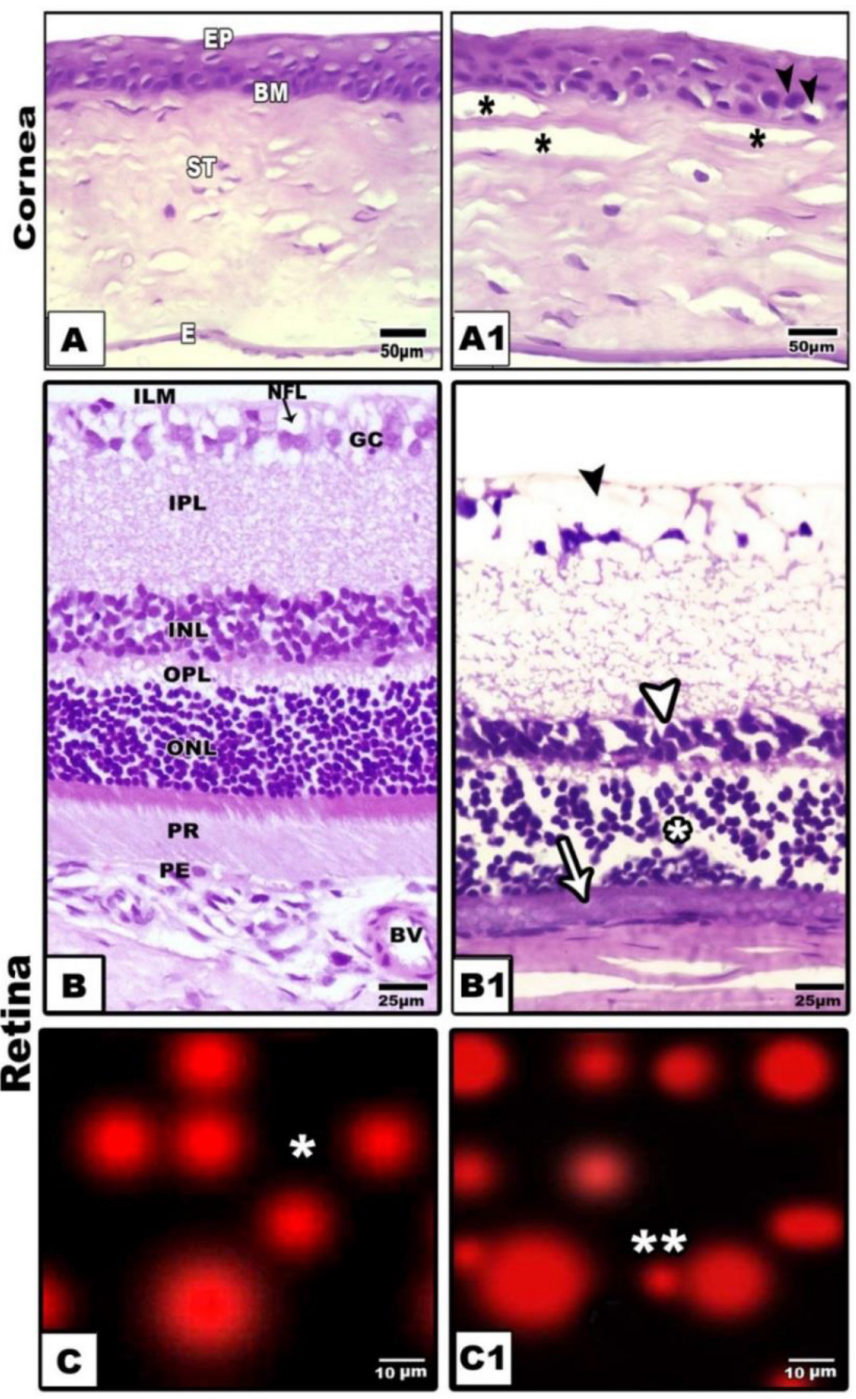

Figure 1. Photomicrographs of cross histological sections of cornea (A\&A1) and retina (B\&B1). A. Control showing normal epithelium, basement membrane, stroma and endothelium. B. Diabetic showing thickened epithelium, damaged stroma and thickened endothelium. B. Control retina showing arranged ganglion, inner plexiform, inner nuclear, outer plexiform, outer nuclear and photoreceptor layers. B1. Diabetic retina showing damaged ganglion, thinning inner nuclear (arrow head), damaged outer nuclear (star) and atrophied photoreceptor(arrow) C \& A1. Comet assay of control (single star)(C) and cataractous (double star) (C1) retina showing detached retinal cells of diabetic group. Abbreviations; E, endothelium;BM, basement membrane; IPL, inner plexiform layer; ILM, inner limiting membrane; INL, inner nuclear layer; NFL, nerve fiber layer; OPL, outer plexiform layer; ONL, outer nuclear layer; PR, photoreceptor; Pg, pigmented cell; St, stroma.

Diabetic-treatment revealed widespread of vacuoles and fragility of the nerve fibers, and comparative reduction of the oligodendrocytes. Many of them possessed vacuolated axoplasm (Fig. 3D). Ultrastructurally, vacuolation and demyelination of the theaxonal sheath were detected (Fig. 3 D1). Following application comet assay, there was apparent increase of apoptic cells with detached tail region (Fig.3D2) compared to non-changed in control (Fig.3C3). 


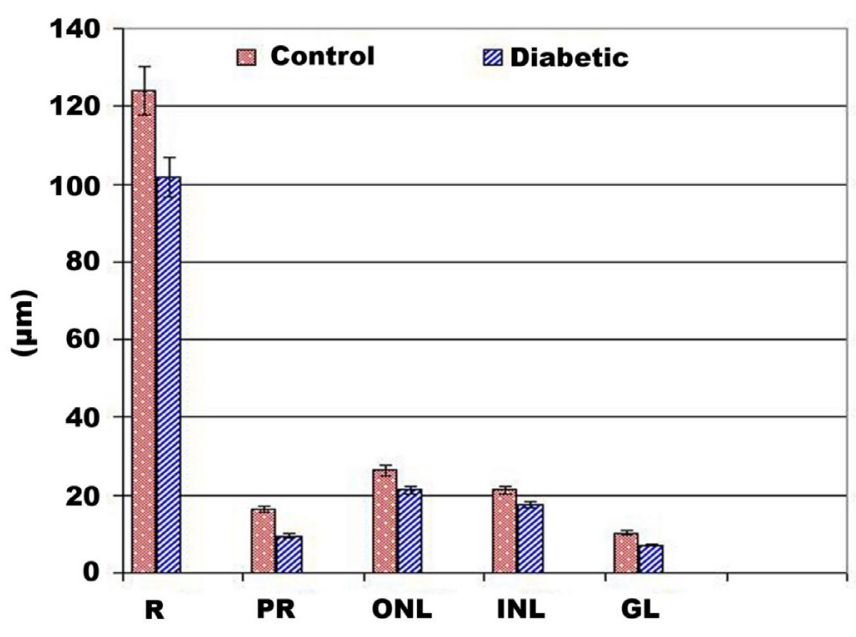

Figure 2. Chart illustrated retinal layer thickness of diabetic group. Abbreviations; GL, gamglion layer; INL, inner nuclear layer; ONL, outer nuclear layer; PR, photoreceptor; R, retina. each result represent mean $\pm S D(n-5)$. Diabetic retina and photoreceptor thickness are significant in diabetic group at $\mathrm{P}<0.05$.

\section{Meibomian gland}

In control, the meibomian gland consisted of numerous branched acini that opened into a central duct through short ductules. Each acinus consisted of a basal layer of flattened cells. The central duct was lined by stratified squamous epithelium (Figs.4A1-A3).

In diabetic group, the gland exhibiteda considerable atrophy and degeneration of the acinar cells (Figs. 4B1-B3).

Following immunohistochemical investigations, bcl2 revealed marked depletion of the immunostaining reaction in the gland of diabetic rats compared to the increased expression in the control (Fig.5A\&B). On the other hand both caspase 3 and P53 were over expressed in those of diabetic mother manifesting cell death (Figs. 5) in comparison with the control (Figs. 5A1, A2, B1 \&B2). Image analysis revealed decreased bcl 2 and increased both caspase 3 and p53 active area of immunohistochemical reaction those of diabetic mothers in comparison with the control (Fig.6).

\section{Discussion}

The diabetes mellitus (DM) is a public health problem widely increased among population. The present findings revealed induction of cataractous lenses of $6 / 47$ individuals with about $13 \%$.

The present findings agree with the work of El-Sayyad et al. [3739], Becker et al. [5] and Wu et al. [6] in human and El-Sayyad et al. [37] and Miller and Brines [7] in experimental animals.

Development of cataractous lenses in diabetic patients was found to result from damaging of lens epithelium $[37,40]$ associated with releasing of free radicals and reduction of the capacity of both antioxidant enzymes and aldose reductase [39, 41] altering glucose metabolism and accumulation of sorbitol enhanced cell damage and development of cataract $[39,42,43]$.

Also, diabetic cataract was found to be associated with corneal damage assessed by thickened epithelial lining layer, necrotic stromal patches and thickened endothelium.
The present findings supported the work of Olsen and Busted [22] and Hashemi et al. [23] that reported increased corneal thickness in diabetic patients. Diabetic keratopathy was also, mentioned by Bikbova et al. [24] which impaired the corneal sensitivity. Alterations of diabetic cornea may contribute to damage of the corneal nerve fibers $[20,44]$ and progress the development of anterior segment disorders [21] resulting in impairing the vision.

Also, the diabetic retina attained a comparatively reduced thickness; numerical reduction of inner and outer nuclear cells and atrophied photoreceptors coincides with increased detached retinal cells manifested DNA damage.

The observed diabetic retinopathy supported the work of ElSayyad et al. [37], Kim and Yu [33], Yao et al. [12] and Li et al [10]. The authors mentioned that the retinopathy impaired the visual acuity and the development of blindness. Diabetic retinopathy related to blindness affected about 800 cases each year [45].

At the same time, the detected atrophy and damaged photoreceptors supported the work of Johnson et al. [16] and El-Sayyad et al. [37].

Diabetic retinopathy was found to exhibit over expression of inflammatory markers, down-regulation of antioxidant enzymes associated with increased retinal cell death $[13,14,17]$.

The present data revealed that diabetes caused abnormal nonbranched biliary processes and reduced thickness of their lining epithelium parallel with single strand DNA damage. The present findings agree with [33] following investigating diabetic patients.

Ciliary organ is important for contraction and relaxation of lens allowing it for accommodation. Damage of ciliary epithelium and defect of collagenous fibrils of the ciliary lumina interfered with retinal dystrophies [46].

The present findings revealed neuropathy of optic nerve of diabetic rat assessed by fragility and degeneration of nerve fibers, demyelinated axons and decrease of neuronal cells coincides with single strand DNA damage of astrocytes. Similar findings of optic neuropathy were detected in aging rats which exhibited similar diabetic deterioration of the neuronal cells [47].

Diabetes associated microvascular abnormalities may facilitate the progress of ischemia of the anterior optic nerve [48].

On the other hand the meibomian glands are important for ocular function through secretion of oily meibum which lubricate the ocular surfaces and protecting against tear evaporation [49].

The present findings revealed that diabetes induced atrophy and degeneration of meibomian glands. Following immunohistochemical staining, decreased expression of bcl2 and overexpression of caspase 3 and $\mathrm{p} 53$, the markers of cell death were detected.

Similar findings of diabetes associated meibomian gland dysfunction were reported [28, 31, 32]. Decreased lipid secretion was found to be associated with the instability of tear and progress of dry eye disease [27, 30].

Finally the authors concluded that the cataractous lenses originated through different pathways of diabetic complication. 

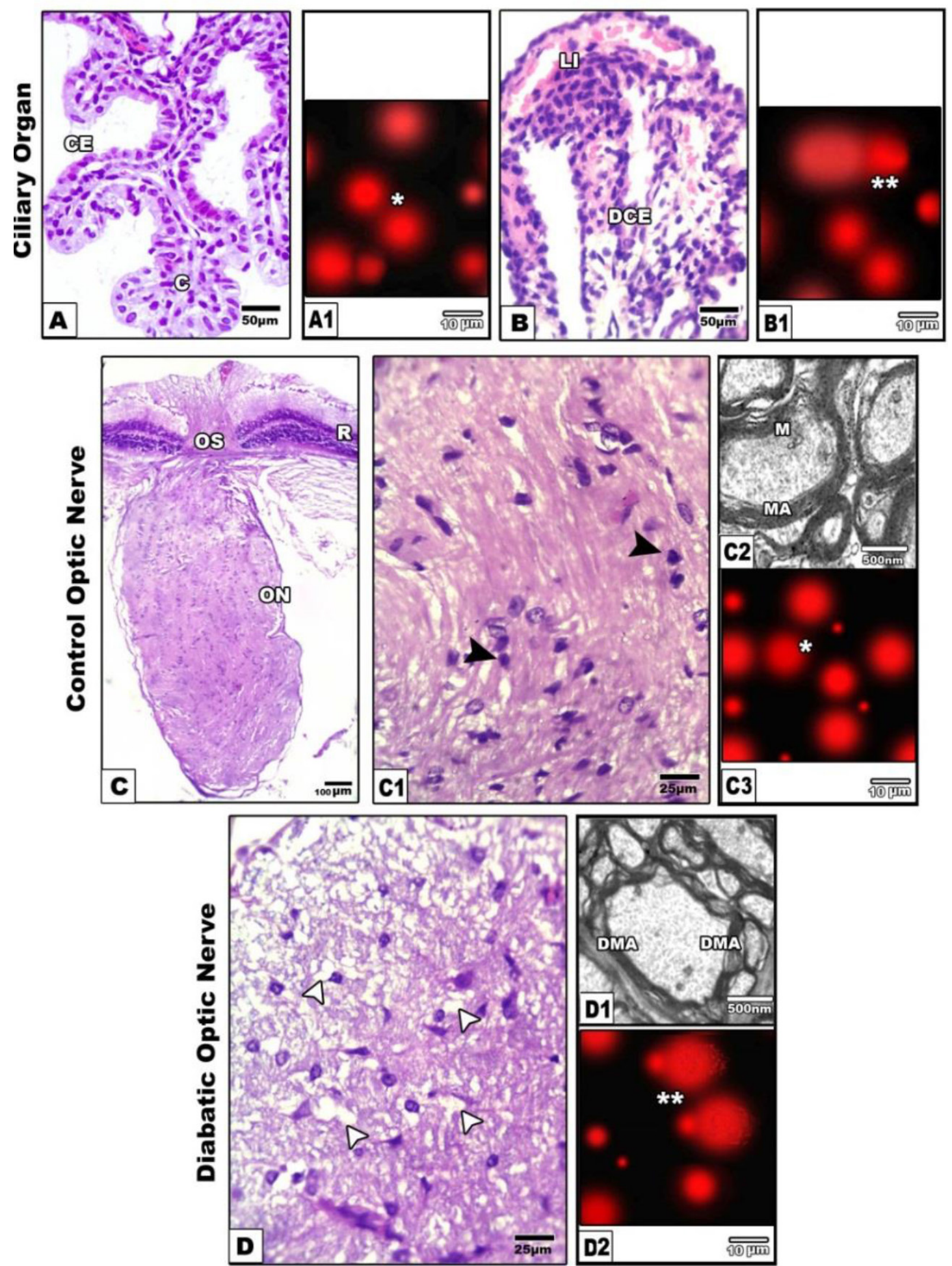

Figure 3A-B1. Photomicrographs of histological sections of ciliary organ. A. Control showing branched ciliary organ. A1. Comet assay of control showing normal round cells (single star). B\&B1. Diabetic rat showing atrophied ciliary organ (B) with detached damaged cells post comet assay (double star) (B1).

Figure 2C-C1. Photomicrographs of histological sections of control optic nerve showing attachement with retina in optic disc and compacted axons and contents of neuronal cells(dark arrow head).C2. Transmission electron micrographs of control showing compacted myelinated axons. C3. Comet assay of control showing round cells (Single star). D-D2 Diabetic group showing fragile histological section and vacuolated neurons (white arrow head) (D) and demyelinated electron micrograph (D1) and detached neuronal cells of optic nerve after comet assay (D2). Abbreviations; C, connective tissue; CE, ciliary epithelium; DCE, damaged ciliary epithelium; DMA, degenerated mitochondrial axons.LI, lymphocytic infiltration; M, mitochondria; MA, mitochondrial axons; 
Normal
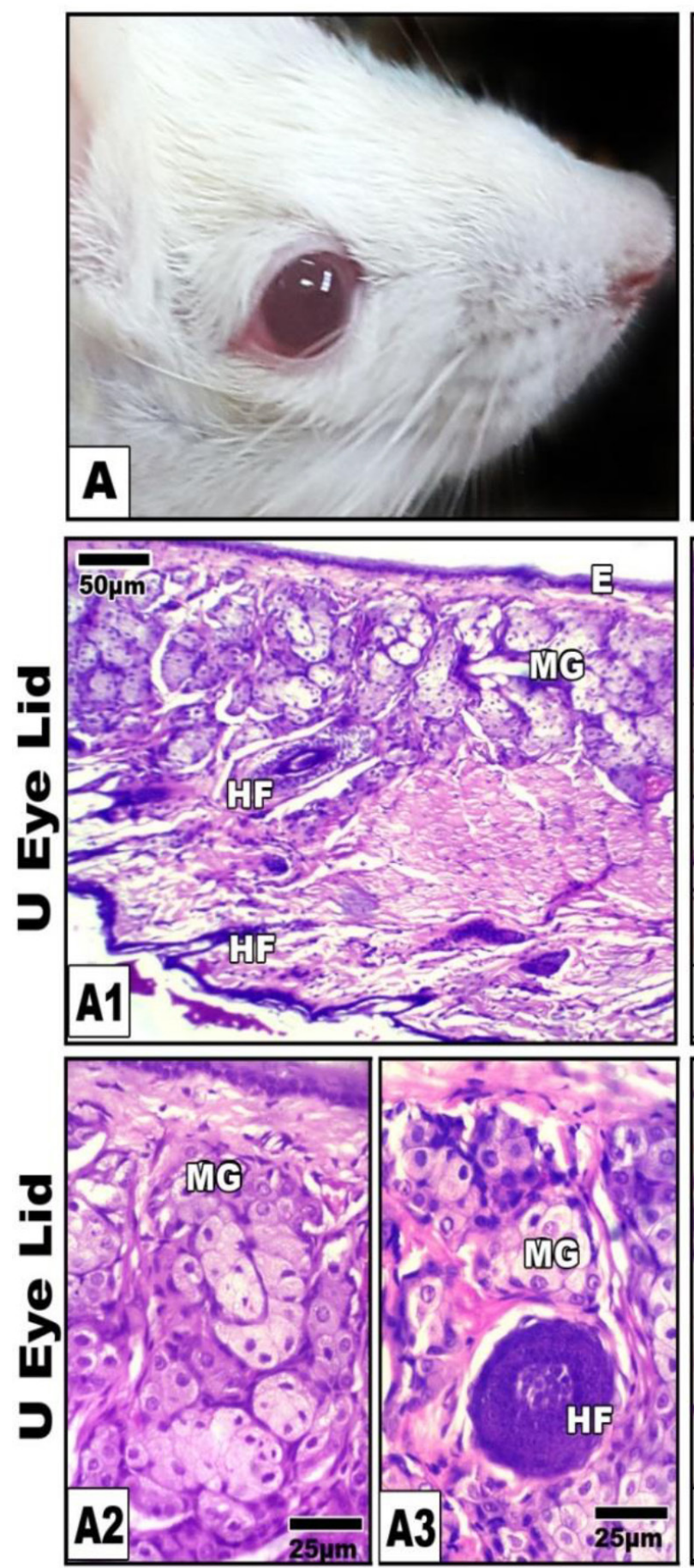

Diabatic
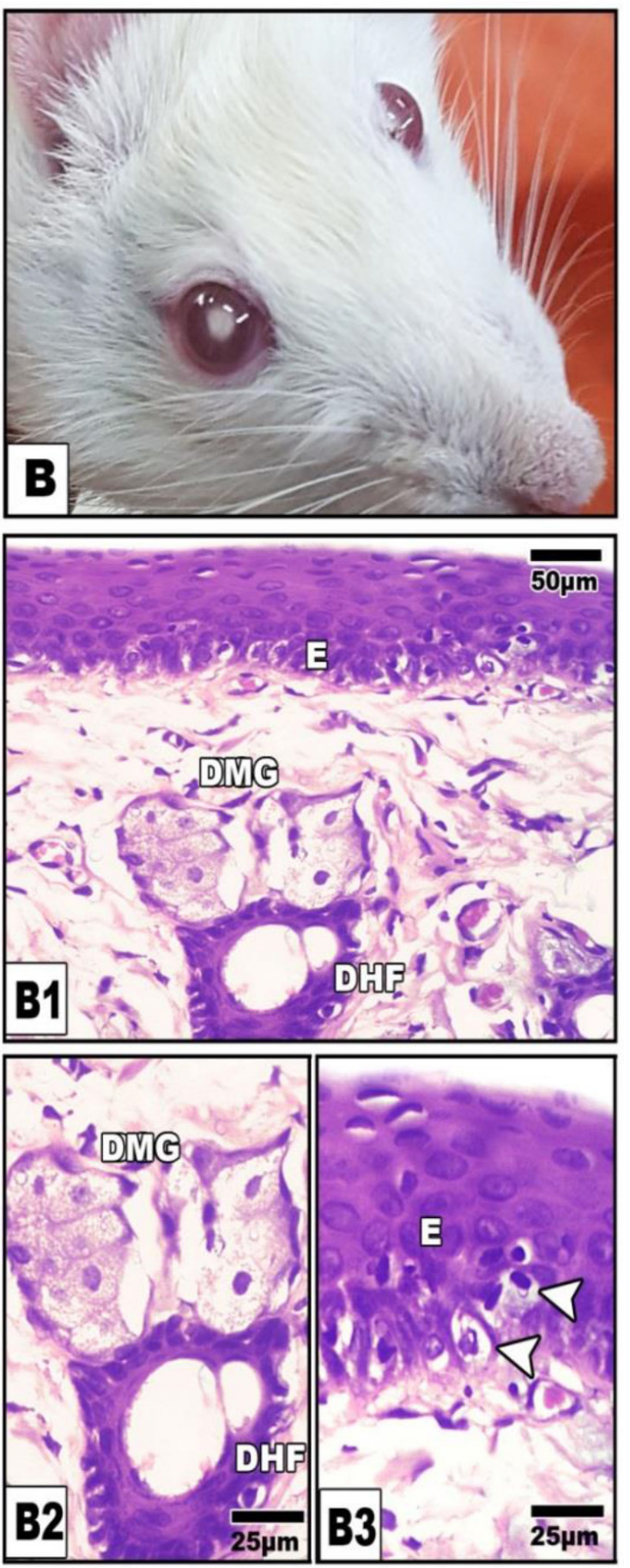

Figure 4. A, Photomacrograph of normal (A) and diabetic cataract (B).A1-A3. Photomicroph of histological sections of control meibomian gland showing normal branched acinar gland. B1-B3. Diabetic rat showing atrophied and degenerated meibomian gland (B1\&B2) and degenerated germinativum of epidermis (B3) illustrated by arrow head. Abbreviations; DHf, degenerated hair follicle ; DMG, damaged meibomian gland; E, epidermis; HF, hair follicle ; MG, meibomian gland.HE 
Normal
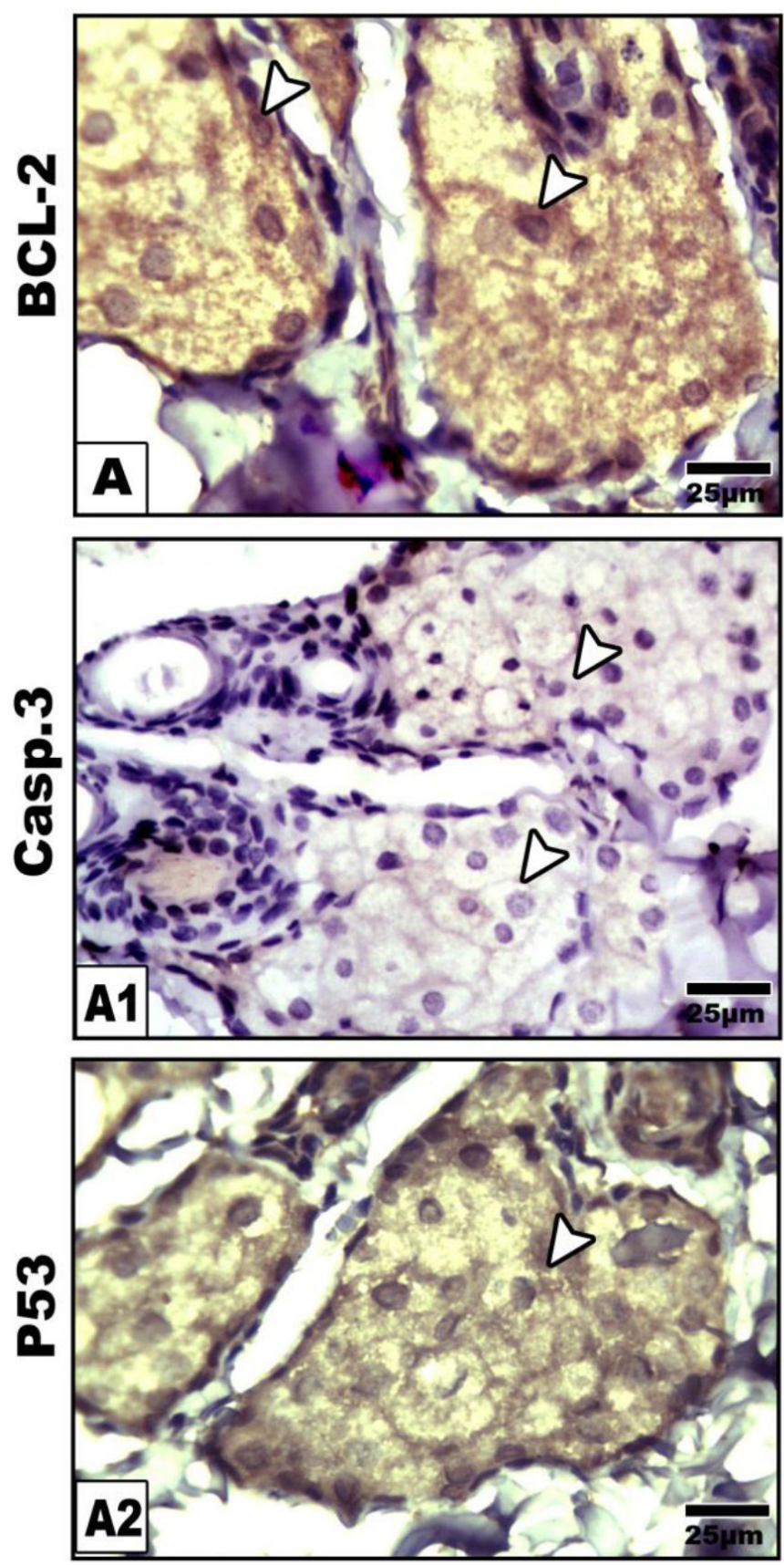

Diabatic
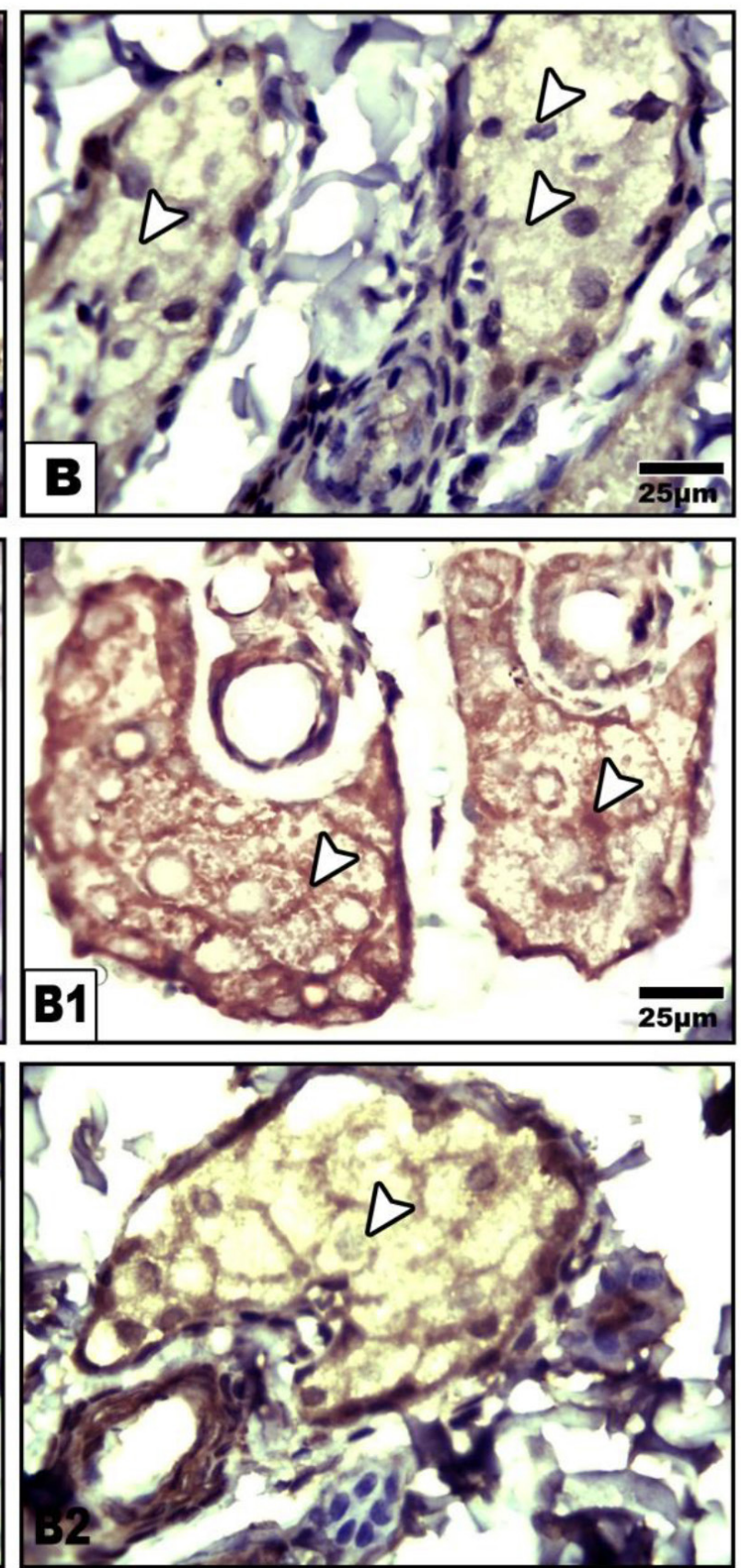

Figure 5. Photomicrographs of formalin fixed histological sections of meibomian glands immunohistochemical stained with Bcl2(A\&B), Caspase 3 (A1 \&B1) and P53 (A2 \&B2). Note decreased expression of Bcl2 (B), increased expression of caspase 3( B1) and overexpression of p53 (B2) in diabetic group compared to control (A-A2). Arrow head pointed to the immunostaining activity. 


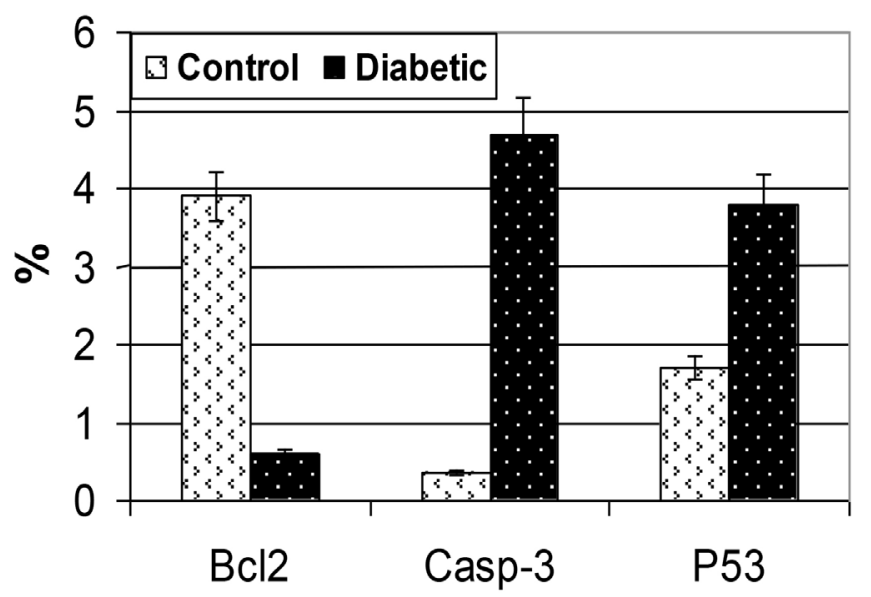

Figure 6. Chart illustrating of the image analysis of percentages immunoreactive area of diabetic group in comparison with the control. Each result represent the mean $\operatorname{SD}(n=5)$. Diabetic is significant at $\mathrm{P}<0.05$.

\section{References}

1. Wild S, Roglic G, Green A, Sicree R, King H (2004) Global prevalence of diabetes: estimates for the year 2000 and projections for 2030. Diabetes Care 27: 1047-53.

2. Aguiree F, Brown A, Cho NH, Dahlquist G, Dodd S et al. C (2013) IDF Diabetes Atlas.

3. Al-Goblan AS, Al-Alfi MA, Khan MZ (2014) Mechanism linking diabetes mellitus and obesity. Diabetes MetabSyndrObes 7: 587-91.

4. Kalra S, Singh RR (2018) Visual acuity assessment in diabetes. J Pak Med Assoc 68: 1407-1409.

5. Becker C, Schneider C, Aballéa S, Bailey C, Bourne R et al. (2018) Cataract in patients with diabetes mellitus-incidence rates in the UK and risk factors. Eye (Lond) 32: 1028-1035.

6. Wu J, Zeng H, Xuan R, Lei S, Li J et al (2018) Bilateral cataracts as the first manifestation of type 1 diabetes mellitus: A case report. Medicine (Baltimore) 97 : 12874 .

7. Miller EJ, Brines CM (2018) Canine Diabetes Mellitus Associated Ocular Disease. Top Companion Anim Med 33: 29-34.

8. Chen Z, Song F, Sun L, Zhao C, Gao N et al (2018) Corneal integrity and thickness of central fovea after phacoemulsification surgery in diabetic and nondiabetic cataract patients. Arch Med Sci 14: 818-825.

9. Kim C, Yu HG (2012) Changes in ciliary body thickness in patients with diabetic macular edema after vitrectomy. Retina 32: 1316-23.

10. Li Z, Alzogool M, Xiao J, Zhang S, Zeng P et al. (2018) Optical coherence tomography angiography findings of neurovascular changes in type 2 diabetes mellitus patients without clinical diabetic retinopathy. ActaDiabetol 55: 1075-1082.

11. Tawfik A, Mohamed R, Elsherbiny NM, DeAngelis MM, Bartoli M et al (2019) Homocysteine: A potential biomarker for diabetic retinopathy. J Clin Med 8: 121.

12. Li Q, Yang Y, Lu X, Zhang Q, Luo M et al (2018) Lycium Barbarum Polysaccharides improve retinopathy in diabetic Sprague-Dawley rats. Evid Based Complement Alternat Med 2018: 7943212.

13. Amato R, Rossino MG, Cammalleri M, Locri F, Pucci L et al (2018) Protects the retina from neurovascular damage in experimental diabetic retinopathy. Nutrients 10: 1932.

14. Ola MS, Alhomida AS, LaNoue KF (2019) Gabapentin attenuates oxidative stress and apoptosis in the diabetic rat retina. Neurotox Res.

15. Dmitriev AV, Henderson D, Linsenmeier RA (2019) Diabetes alters pH control in rat retina. Invest Ophthalmol Vis Sci 60: 723-730.

16. Johnson MA, Lutty GA, McLeod DS, Otsuji T, Flower RW et al (2005) Ocular structure and function in an aged monkey with spontaneous diabetes mellitus. Exp Eye Res 80: 37-42.

17. Ren C, Wu H, Li D, Yang Y, Gao Y et al. (2018) Remote Ischemic Conditioning Protects Diabetic Retinopathy in Streptozotocin-induced Diabetic Rats via AntiInflammation and Antioxidation. Aging Dis 9: 1122-1133.

18. Yang F, Yu J, KeF, Lan M, LiD et al (2018)Curcumin alleviates diabetic retinopathy in experimental diabetic rats. Ophthalmic Res 60: 43-54.

19. Lagali NS, Allgeier S, Guimarães P, Badian RA, Ruggeri A et al (2017) Reduced corneal nerve fiber density in type 2 diabetes by wide-area Mosaic analysis. Invest Ophthalmol Vis Sci 58: 6318-6327.
20. Bikbov MM, Surkova VK (2019) Prognostic value of changes in the cornea and conjunctiva in diabetes mellitus. VestnOftalmol 135: 90-97.

21. Han SB, Yang HK, Hyon JY (2018) Influence of diabetes mellitus on anterior segment of the eye. ClinInterv Aging 14: 53-63.

22. Olsen T, Busted N (1981) Corneal thickness in eyes with diabetic and non diabetic neovascularisation. Br J Ophthalmol 65: 691-3.

23. Hashemi H, Asgari S, Mehravaran S, Emamian MH, Fotouhi A (2019) FiveYear Changes of Anterior Corneal Indices in Diabetics versus Non-Diabetics: The Shahroud Eye Cohort Study. Curr Eye Res 44: 30-33.

24. Bikbova G, Oshitari T, Baba T, Bikbov M, Yamamoto S (2018) Diabetic corneal neuropathy: clinical perspectives. ClinOphthalmol 12: 981-987.

25. Knop N, Knop E (2009) Meibomian glands. Part I: anatomy, embryology and histology of the Meibomian glands. Ophthalmologe 106: 872-83.

26. Bolekova A, Kluchova D, Tomasova L, Hvizdosova N (2012) Effect of retinoic acidon the nitrergic innervations of Meibomian glands in rats. Eur J Histochem 56: 50 .

27. Knop E, Knop N, Millar T, Obata H, Sullivan DA (2011) The international workshop on meibomian gland dysfunction: report of the subcommittee on anatomy, physiology, and pathophysiology of the meibomian gland. Invest Ophthalmol Vis Sci 52: 1938-1978.

28. Seirafi H, Farsinejad K, Firooz A, Davoudi SM, Robati RM et al (2009) Biophysical characteristics of skin in diabetes: a controlled study. $J$ EurAcadDermatolVenereol 23:146-149.

29. Shamsheer RP, Arunachalam C (2015) A Clinical Study of Meibomian Gland Dysfunction in Patients with Diabetes. Middle East Afr J Ophthalmol 22: 462-6.

30. Baudouin C, Aragona P, Messmer EM, Tomlinson A, Calonge M et al. (2013) Role of hyperosmolarity in the pathogenesis and management of dry eye disease: proceedings of the OCEAN group meeting. Ocul Surf 11: 246-58.

31. Ding J, Liu Y, Sullivan D (2015) Effects of insulin and high glucose on human meibomian gland epithelial cells. Invest Ophthalmol Vis Sci 56: 7814-7820.

32. Lin X, Xu B, Zheng Y, Coursey TG, Zhao Y et al (2017) Meibomian Gland Dysfunction in Type 2 Diabetic Patients. J Ophthalmol 2017: 3047867.

33. Kim C, Yu HG (2012) Changes in ciliary body thickness in patients with diabetic macular edema after vitrectomy. Retina 32: 1316-23.

34. Cao D, Yang D, Yu H, Xie J, Zeng Y et al (2019) Optic nerve head perfusion changes preceding peripapillary retinal nerve fibre layer thinning in preclinical diabetic retinopathy. ClinExpOphthalmol 47: 219-225.

35. Ghasemi A, Khalifi S, Jedi S (2014) Streptozotocin-nicotinamide-induced rat model of type 2 diabetes. ActaPhysiol Hung 101:408-20.

36. Sasaki YF, Saga A, Akasaka M, Yoshida K, Nishidate E et al (1997) In vivo genotoxicity of ortho-phenylphenol, biphenyl, and thiabendazole detected in multiple mouse organs by the alkaline single cell gel electrophoresis assay. Mutat Res 395:189-98.

37. El-Sayyad HIH, El-Sherbiny M, Sobh MA, Abou-El-Naga AM, Ibrahim MAN et al (2011) Protective effects of Morus alba leaves extract on ocular functions of pups from diabetic and hypercholesterolemic mother rats. Int.JBiolSci 7: 715-728.

38. El-Sayyad HIH, Bakr EHM, El-Ghawet HA, El-Desoky TMG (2015) Overview of congenital, senile and metabolic cataract J Ocular Biol 3: 12.

39. El-Sayyad HI, Tag-Eldin YM, Khalifa SA, Abd- El-Wahab AA, El-Desoky TMG (2017) Biochemical and molecular markers of congenital and senile cataractous lenses. J MolBiomarkDiagn 8: 318.

40. Tkachov SI, Lautenschlager C, Ehrich D, Struck HG (2006) Changes in the lens epithelium with respect to cataractogenesis: light microscopic and Scheimpflug densitometric analysis of the cataractous and the clear lens of diabetics and nondiabetics. Graefes Arch ClinExpOphthalmol 244: 596-602.

41. Hashim Z, Zarina S (2012) Osmotic stress induced oxidative damage: possible mechanism of cataract formation in diabetes. J Diabetes Complications 26: 275 279 .

42. Kador PF, Lee JW, Fujisawa S, Blessing K, Lou MF (2000) Relative importance of aldose reductase versus nonenzymatic glycosylation on sugar cataract formation in diabetic rats. J OculPharmacolTher 16: 149-160.

43. Gupta SK, Selvan VK, Agrarwal SS, Saxena R (2009) Advances in pharmacological strategies for the prevention of cataract development. Indian J Ophthalmol 57: 175-183.

44. Lagali N, Wowra B, Dobrowolski D, Utheim TP and Fagerholm P et al (2018) Stage-related central corneal epithelial transformation in congenital aniridiaassociated keratopathy. Ocul Surf 16: 163-172

45. NegiA, Vernon SA (2003) An overview of the eye in diabetes. J Royal Soc Med 96: 266-272.

46. May-Simera H, Nagel-Wolfrum K, Wolfrum U (2017) Cilia - The sensory antennae in the eye. ProgRetin Eye Res 60: 144-180. 
47. El-Sayyad HIH, Khalifa SA, El-Sayyad FI, Al-Gebaly AS, El-Mansy AA et al ( 2014) Aging-related changes of optic nerve of Wistar albino rats. Age (Dordr) 36: 519-32.

48. Flammer J, Orgül S, Costa VP, Orzalesi N, Krieglstein GK et al (2002) The impact of ocular blood flow in glaucoma. Prog Ret Eye Res 21: 359-393.
49. Knop E, Knop N, Millar T, Obata H, Sullivan DA (2011) The international workshop on meibomian gland dysfunction: report of the subcommittee on anatomy, physiology, and pathophysiology of the meibomiangland. Invest Ophthalmol Vis Sci 52: $1938-78$

\section{Citation:}

El-Sayyad HIH, El-Beih ME, Yousra A. Fouda, AljebaliA (2019) Diabetes related cataract and histopathological abnormalities of the ocular regions of Wister albino rats. Endocrinol Diabetes Metab J Volume 3(3): 1-9. 